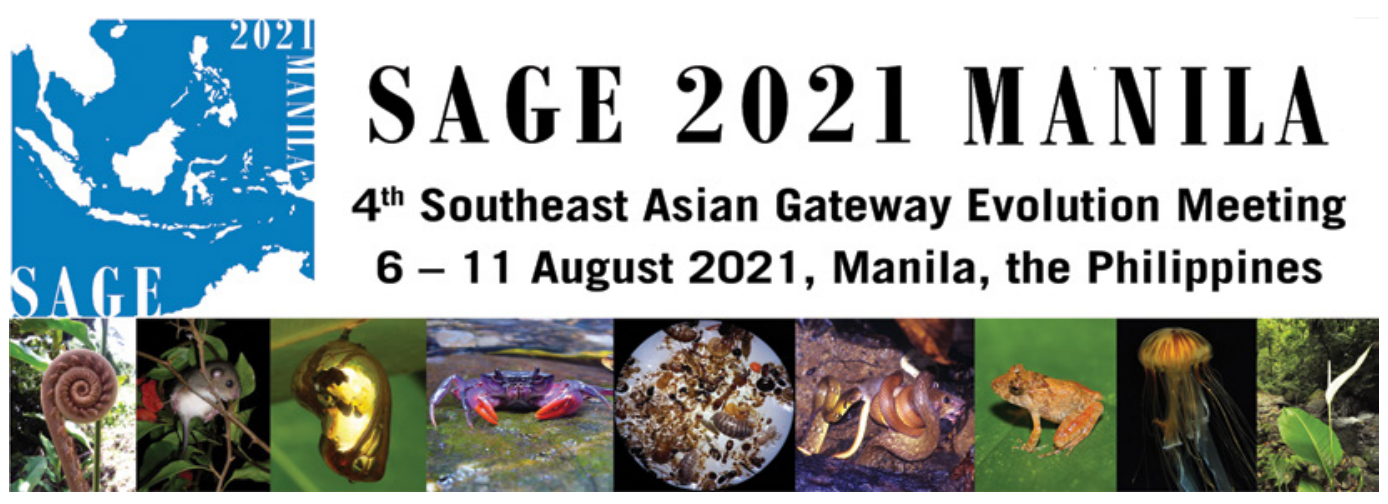

\title{
Conference announcement
}

\section{Hendrik Freitag, Thomas von Rintelen and Jhoana Garces}

\begin{abstract}
Hendrik Freitag \& Jhoana Garces, Biodiversity Laboratory, Department of Biology, School of Science and Engineering, Ateneo de Manila University, 1108 Quezon City, Philippines

Thomas von Rintelen, Museum für Naturkunde, Leibniz Institute for Evolution and Biodiversity Science, Invalidenstraße 43, Berlin, 10115, Germany
\end{abstract}

We cordially invite you to the fourth International Conference on Southeast Asian Gateway Evolution (SAGE 2021; http://www.sage2021.org/) in Manila, the Philippines. This scientific meeting focuses on the origin, diversification, and conservation of Southeast Asia's megadiverse fauna and flora embedded into the context of the region's complex geology and climate history. The gathering used to attract numerous entomologists. We are looking forward to welcoming you to this multidisciplinary meeting with contributions to biodiversity science, biogeography, palaeontology, geology, climatology and conservation. This conference is hosted by the Ateneo de Manila University, a premier private Higher Education and Research Institution in Quezon City, Metro Manila, in collaboration with the Museum für Naturkunde Berlin. The venue inside the green and safe Ateneo campus can be reached conveniently from the airports of Manila and Clark in $30 \mathrm{~min}$ to $2 \mathrm{~h}$.

\section{Schedule and deadlines}

1 January 2021 - Abstract submission and online registration opens

1 April 2021 - Deadline for submission of abstracts and early registration

\section{Organizing committee}

Prof. Dr. Hendrik Freitag (Ateneo de Manila University, Quezon City)

Dr. Thomas von Rintelen (Museum für Naturkunde, Berlin) 
Prof. Dr. Rafe Brown (University of Kansas, Congress office and contact

Lawrence)

Jhoana Garces, Ph.D. \& Emmanuel Delocado, cand.

Marivene Manuel-Santos (Museum of Natural History, National Museum of the Philippines, Manila)

Ph.D. (Ateneo de Manila University, Quezon City),

Prof. Dr. Rudolf Meier (National University of info@sage2021.org.

Singapore) 